\author{
تأثير سطوح مختلف رطوبت خاك در زمان آبيارى بر شاخص هاى \\ رشد اندام هوايى، ريشه، عملكرد و كارايى مصرف آب خيار كلخانهاى \\ عليرضا شفائى '، احمد كريمى ' و رحيم برزگر

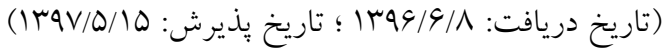

جكيده

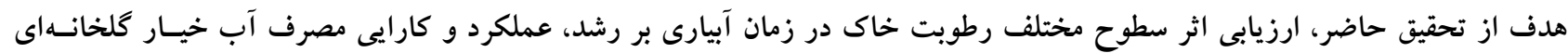

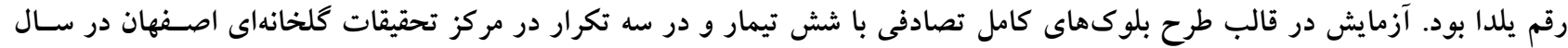

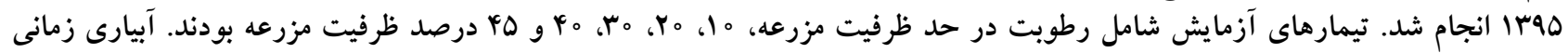

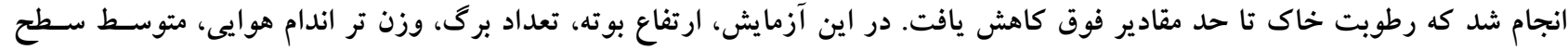

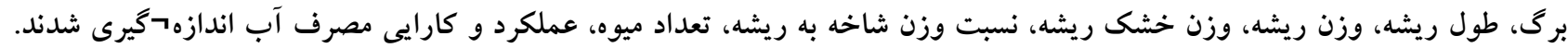

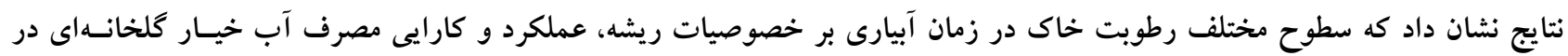

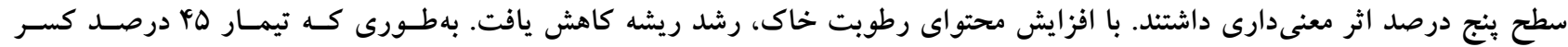

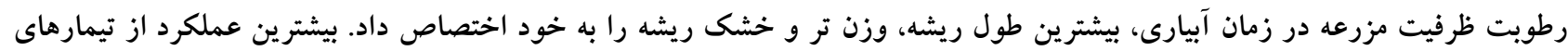

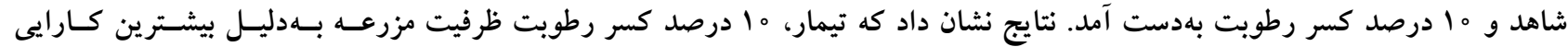

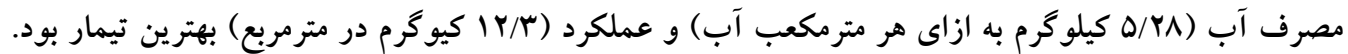

وازههاى كليدى: تعداد ميوه، تنش رطوبتى، ظرفيت مزرعه، عملكرد، نسبت اندام هوايى به ريشه

او Y. بهترتيب دانشجوى كارشناسى ارشد و استاديار، گروه علوم خاك، دانشكده كثاورزى، دانشكاه شهركرد

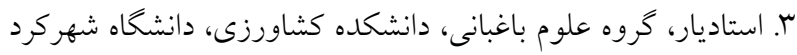
barzegar56@yahoo.com : مسئول مكاتبات: بُست الكترونيكى : 
ريشهها، كاهش سطح برگ يا تعداد بركها و درنهايست سـبب

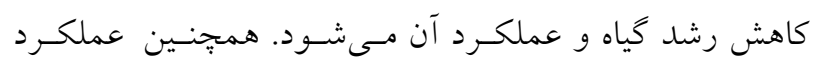

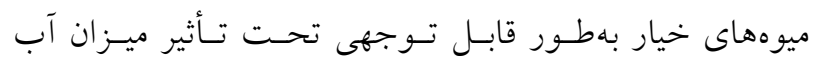

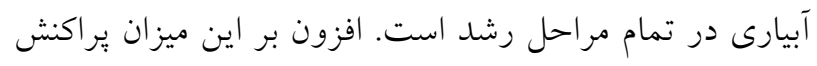

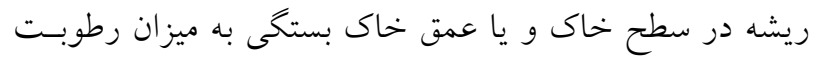

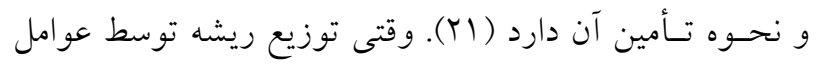

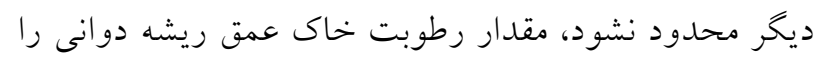

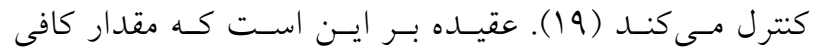
رطوبت در ناحيه ريشه، عامل مهمى براى استفاده كارامد از عناصر غذايى موجود بهشمار مسى آيــــ. زمان، روش و مقدار

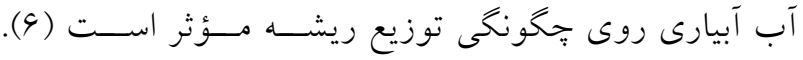

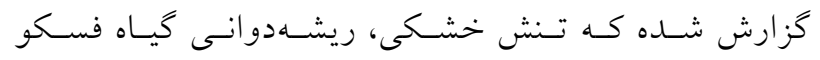

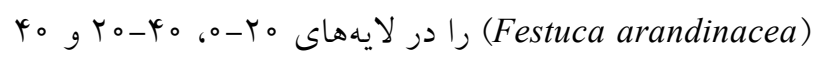

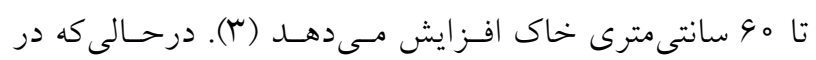

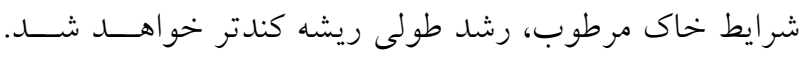

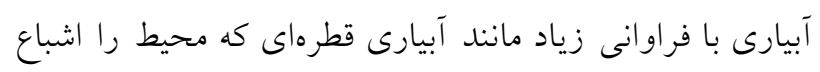

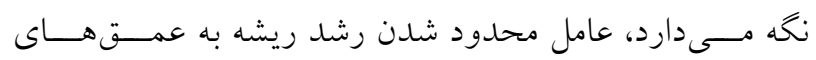

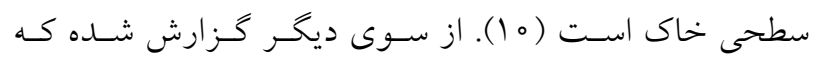

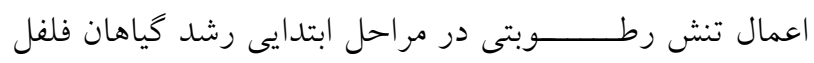
دلمهاى (Capsicum annuum)، خيار (Cucumis sativus) و كدو (Legenaria vulgaris)، موجب بهبود رشد ريشـهــا و عملكرد اين محصو لات شده است (T9).

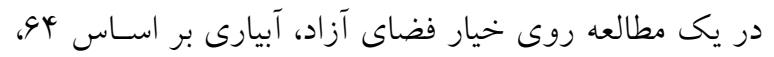
אN و ه O ا درصد ميزان تبخير و تعرق و تيمارهاى كودى شامل

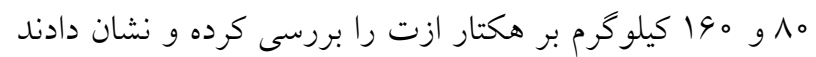

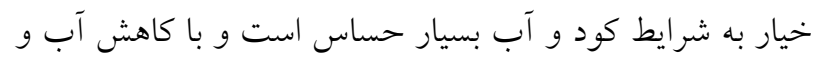

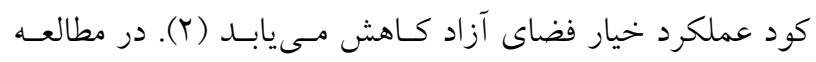

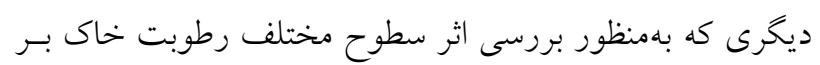

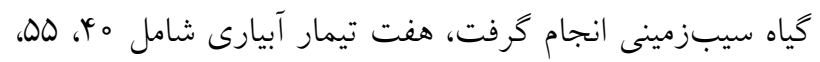

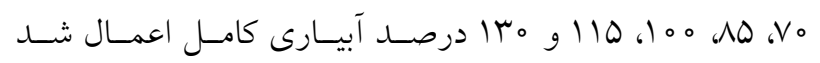

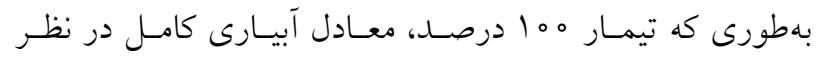

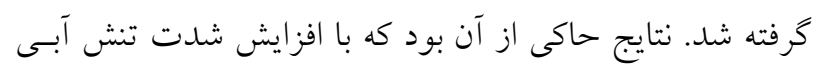

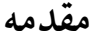

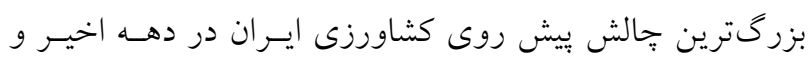

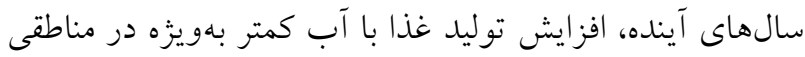

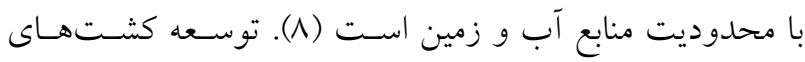

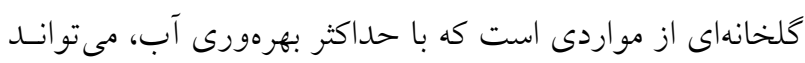

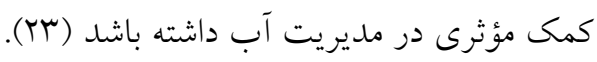

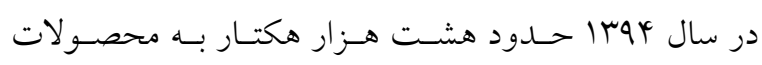

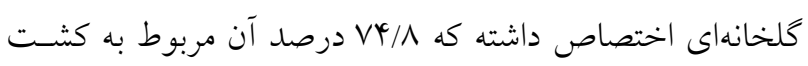

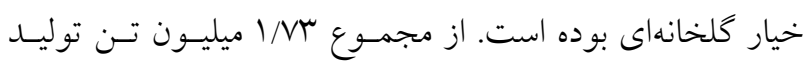

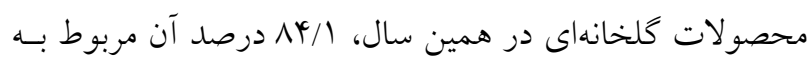

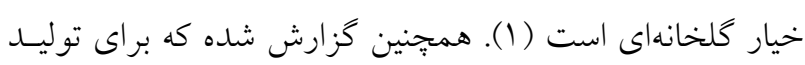

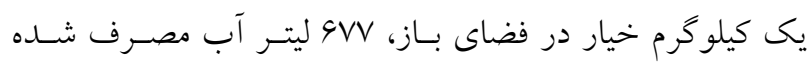

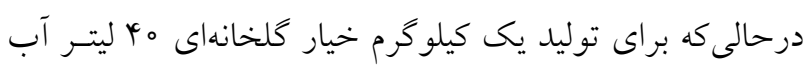

$$
\text { مصرف مىشود (1). }
$$

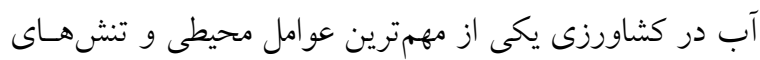

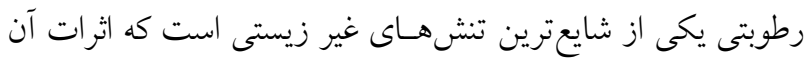

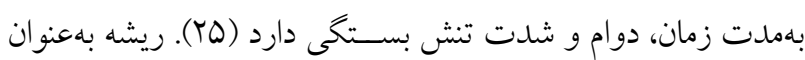

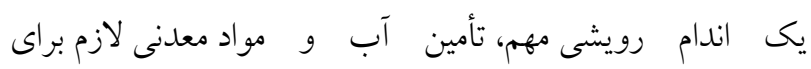

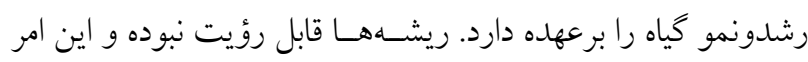

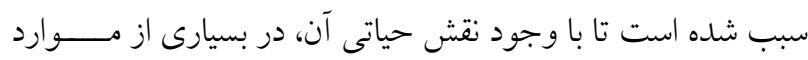
در بررسى شاخصهاى رشد به حساب نيايند (11).

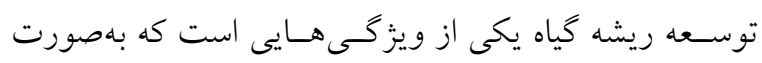

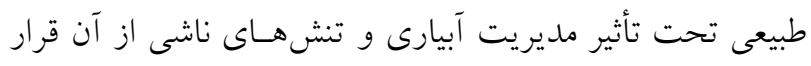

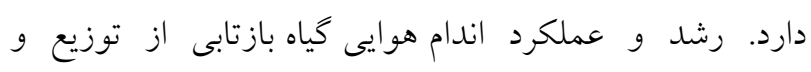

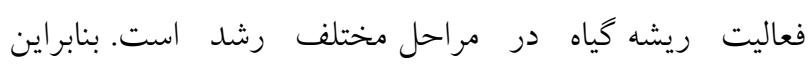

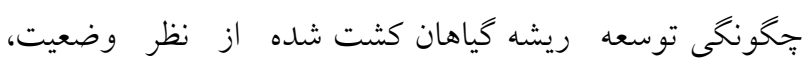

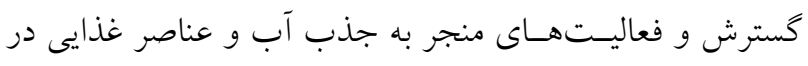

توليد محصولات بسيار مهم است (19).

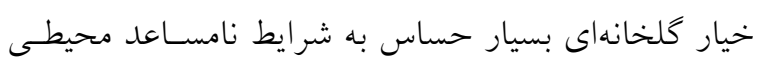

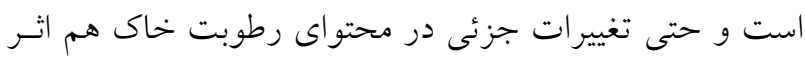

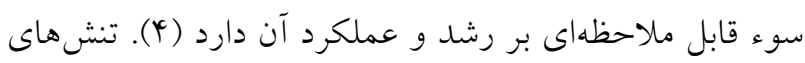

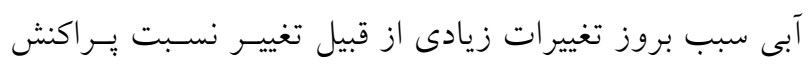


مىشد. سيستم آبيارى بهصـورت قطـرهاى بـا دبسى ك/ه ليتـر در

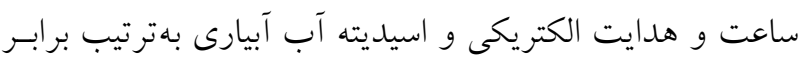

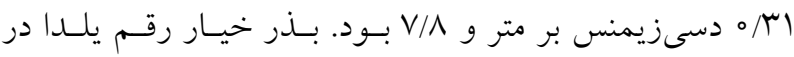

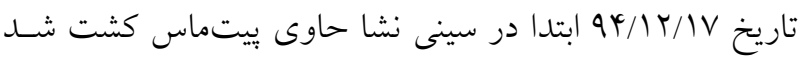

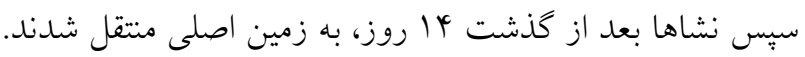

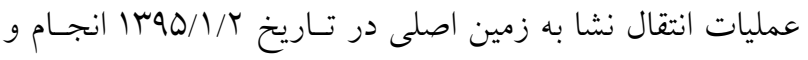

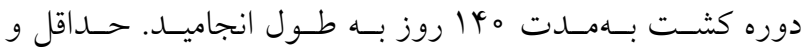
حداكثر دماى كلخانه محل آزمايش در طول شبانهروز بين 1 آتا Y Y درجه سلسيوس تنظيم شد. بـهمنظور اسـتقرار يـافتن كيـاه،

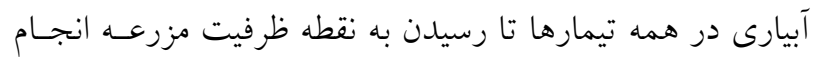

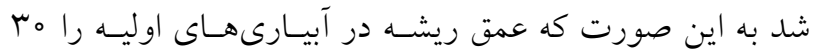

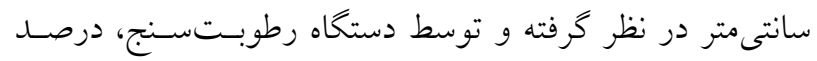

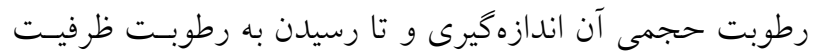

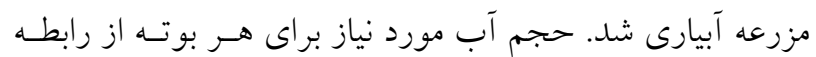
(1) (1) بهدست آمد (10).

$\mathrm{VI}=(\theta \mathrm{mFC}-\theta \mathrm{mi}) \times \rho \mathrm{b} \times \operatorname{Drz} \times \mathrm{A}$

كه در آن VI بيانكر حجم آب مورد نيـاز بـراى هـر بوتـهـ بـر حسب سانتىمتر مكعب، Omi درصد رطوبت وزنسى خـاك در عمق مورد نظر، OmFC درصد رطوبت وزنى در نقطه ظرفيـت فت

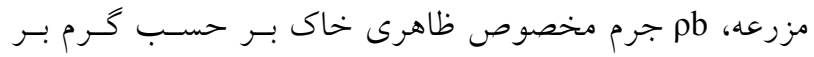
سانتى متر مكعب، Drz عمق ريشه كياه بر حسب سـانتىمتـر و

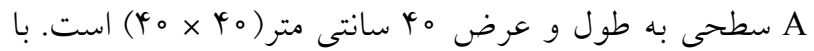

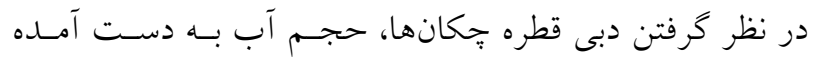
براى هر بوته اعمال شد. عمق توسعه ريشه نسبت به زمـان در

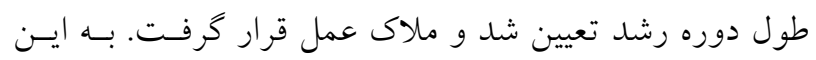
صورت كه در كنار تكرارها، بوتههاى اضافى نيز كشت شــد و

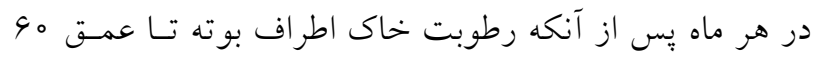

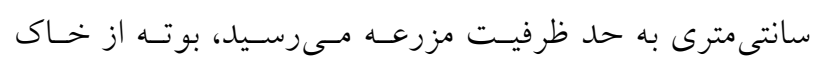

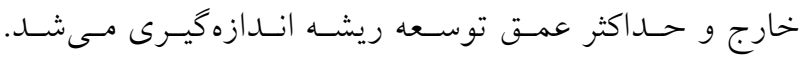

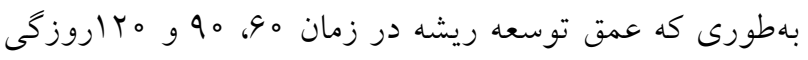

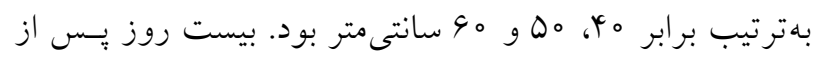

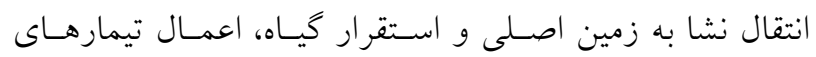

عملكرد و كارايى مصرف آب كاهش يافت (YY).

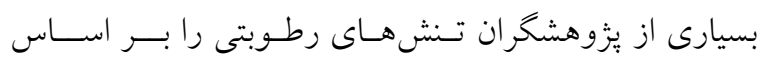

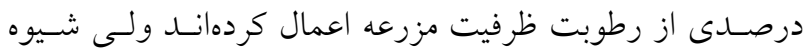
بهكار رفته در اين تحقيق، اعمال تنش بر اساس كسر درصدهاى

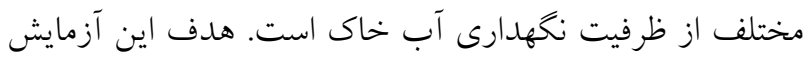

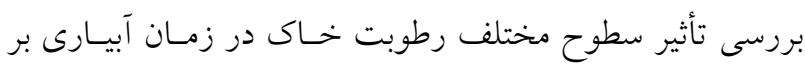
رشد ريشه، عملكرد و كاريى مصرف آب خيار كلخانهاى بود.

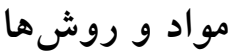

اين يزوهش در مركز تحقيقات كلخانهاى در اصـفهان بـا طـول

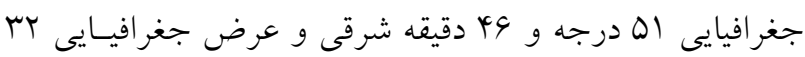

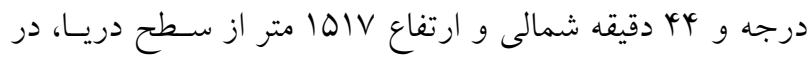

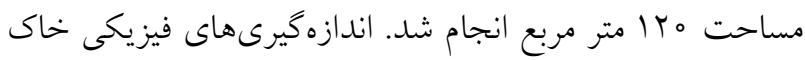

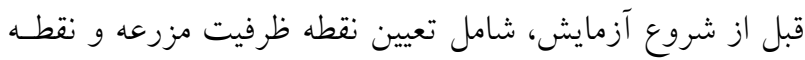

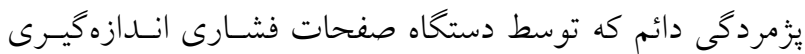
شد. همجنين بافت خاك بمروش هيدرومترى و وزن مخصوص

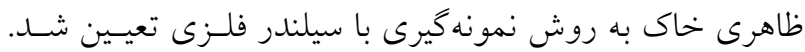

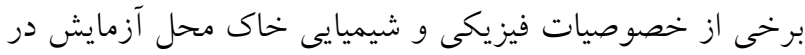
جدول ( ) ارائه شده است.

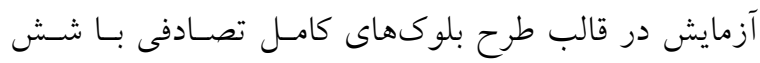

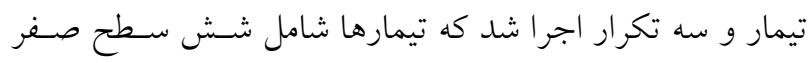

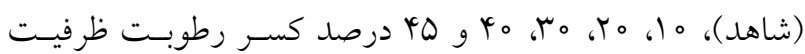
مزرعه بودند. هر واحد آزمايشى داراى سه خط كاشت بـود كـهـ

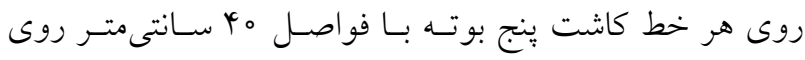

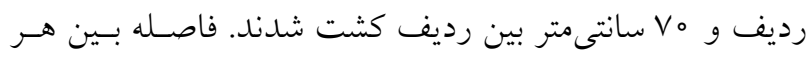

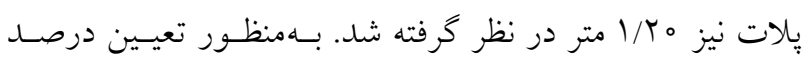

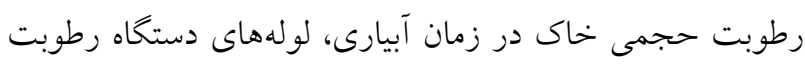

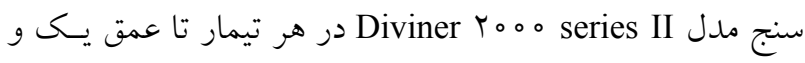
نيم مترى از سطح خاك نصب شد. بـر ايسن اسـاس زمانى كـه

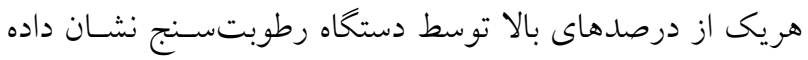

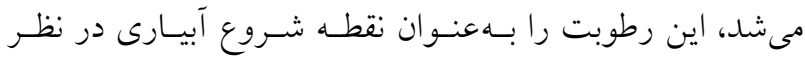

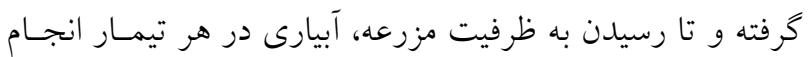


جدول ا. برخى از خصوصيات فيزيكى و شيميايى خاك كلخانه محل آزمايش (عمق صفر تاهب سانتىمتر)

\begin{tabular}{|c|c|c|c|c|c|c|c|c|c|c|c|}
\hline K & $\mathrm{P}$ & $\mathrm{N}$ & $\mathrm{OC}$ & PWP & FC & SP & CEC & $\rho_{b}$ & $\mathrm{EC}$ & $\mathrm{pH}$ & بافت \\
\hline \multicolumn{2}{|c|}{ (ppm) } & \multicolumn{5}{|c|}{$(\%)$} & $\left(\mathrm{Cmol} \mathrm{kg}^{-1}\right)$ & $\left(\mathrm{g} \mathrm{cm}^{-r}\right)$ & $\left(\mathrm{dS} \mathrm{m}^{-1}\right)$ & \multicolumn{2}{|c|}{ - } \\
\hline 011 & 11 & $0 / 19$ & $0 / 91$ & $10 / 1$ & $r \mid / 0$ & is & $19 / \pi$ & $1 / r$ & $r / 9$ & $V / \Gamma$ & رسى شنى \\
\hline
\end{tabular}

دادن درون آون در دماى Vo درجه سلسيوس بهمدت VY ساعت

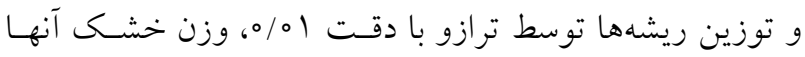
تعيين شد.

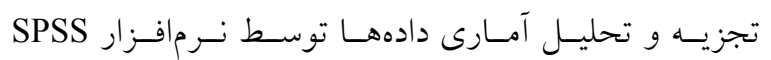

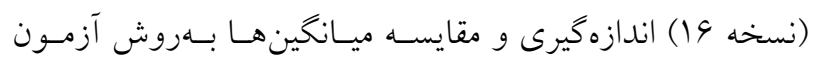
توكى در سطح بنج درصد انجام شد.

\section{نتايج}

نتايج تجزيه واريانس جدول (Y) نشان داد كه سطوح مختلـف

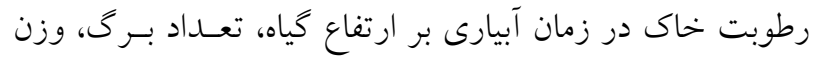
تر اندام هو ايى و سطح برى اثر معنى دارى در سطح يكى درصـــ

داشته است.

\section{رشد اندام هوايى و ريشه}

سطوح مختلف رطوبت خاك در زمان آبيـارى بــر ارتفـاع كيـاه،

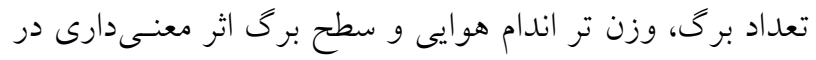

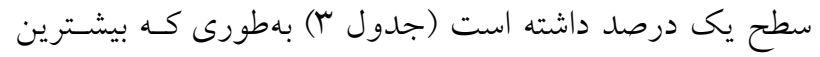

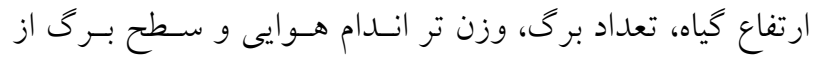

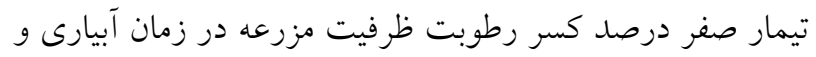

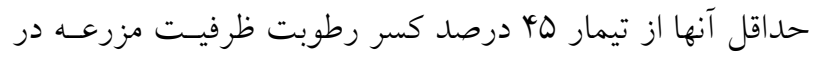

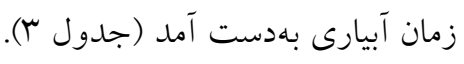

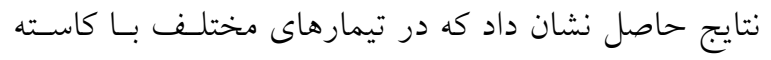

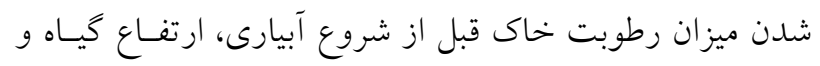
وزن تر اندام هوايى نيز شروع به كاهش كرده است. مسىتـوان

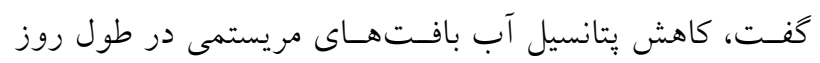

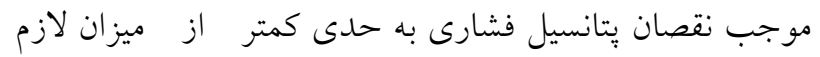

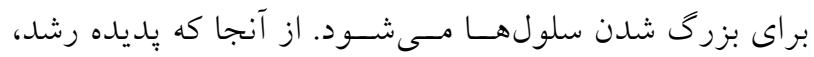

آبيارى آغاز و تا بايان دوره رشد ادامه يافت. بهمنظـور تعيسين عملكرد محصول، ميوه برداشت شده در هر تكرار از هر تيمار

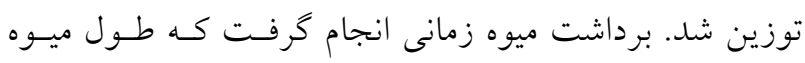

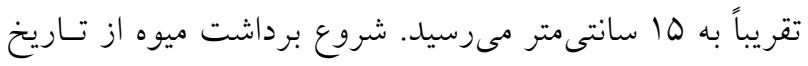

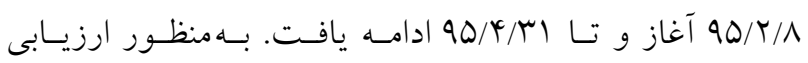
كارايى مصرف آب از رابطه (Y) استفاده شد: $\mathrm{WUE}=\frac{\mathrm{Y}}{\mathrm{W}}$

كه در آن WUE كارايى مصرف آب بر حسب كيلو كُم بـر متسر مكعب، Y مقدار محصول برداشت شده بر حسب كيلـو گرم بـر هكتار و W آب مصرفى بر حسب متر مكعب بر هكتـار اسـت.

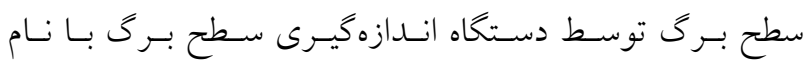
AMrه。Portable Leaf AreaMeter

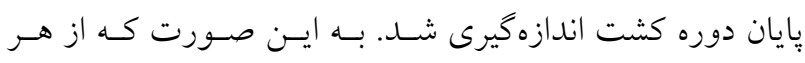

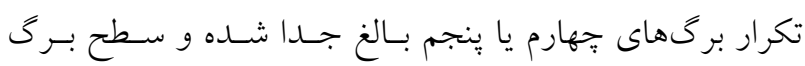

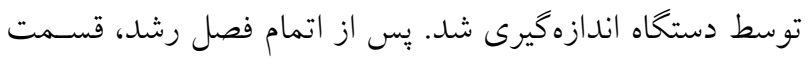

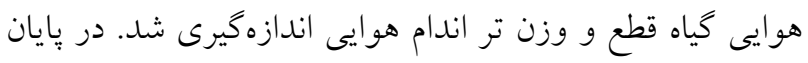

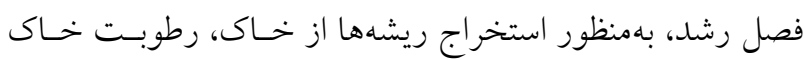

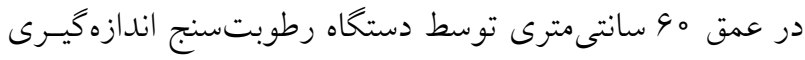

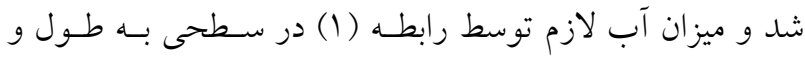
عرض •r سانتىمتر براى رساندن رطوبت محيط ريشه بهميـزان

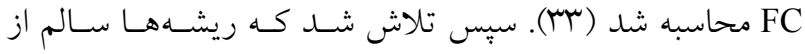

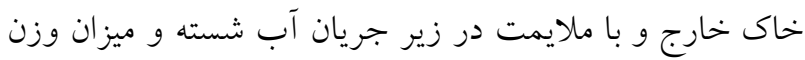

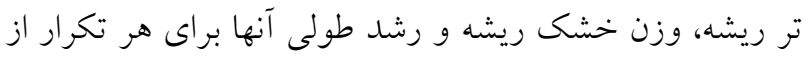

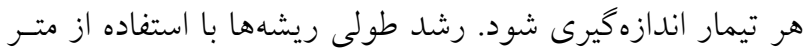

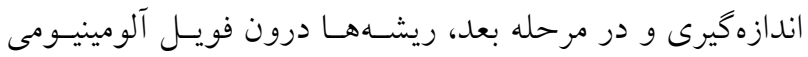

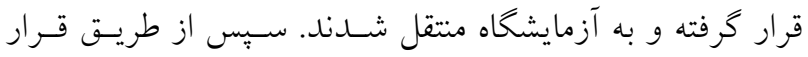




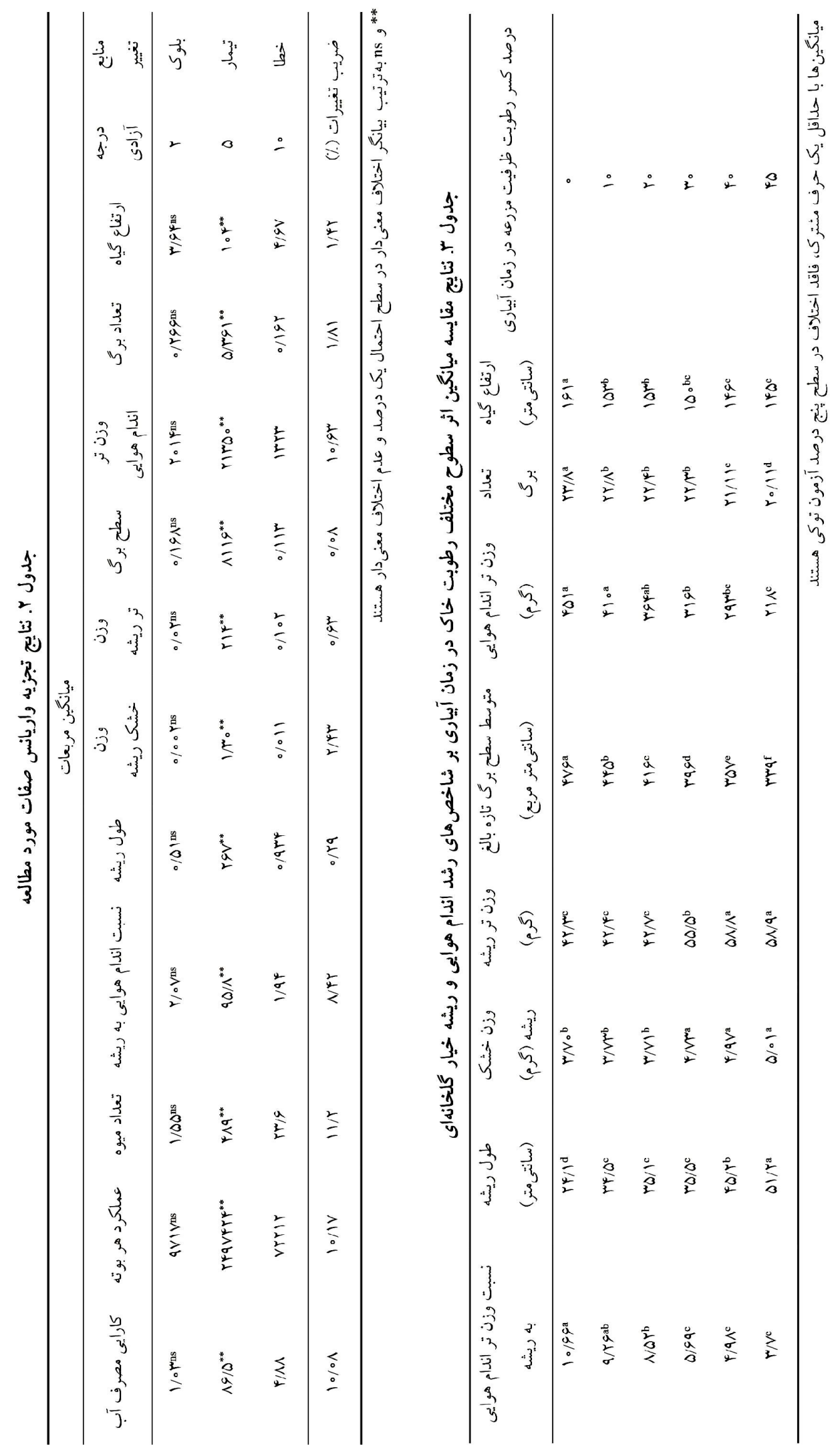


خاك در زمان آبيارى تأثير جشم گيـــى در افـزايش وزن ريشـهـ

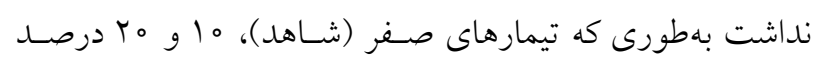
كسر رطوبت ظرفيت مزرعه در زمان آبيارى، اختلاف معنى دارى

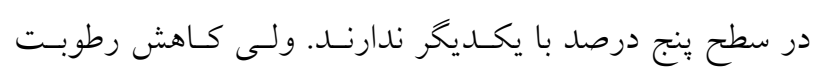

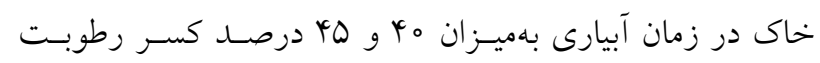

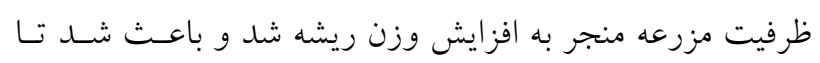

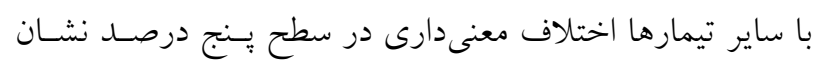
دهند. در بحث رشد اندام هوايى ملاحظه شد كـه تـنش اعمـال

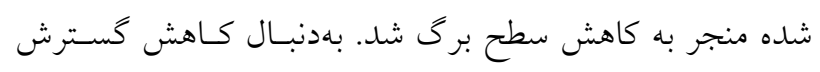

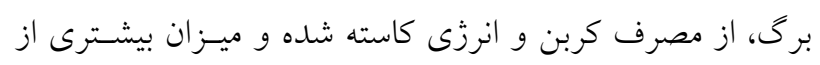

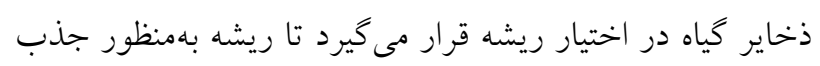

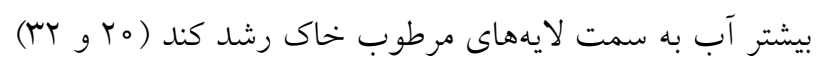

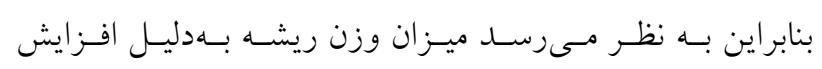
تخصيص اسيميلات به ريشه افزايش يافته است.

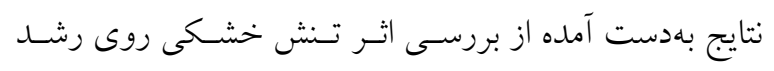

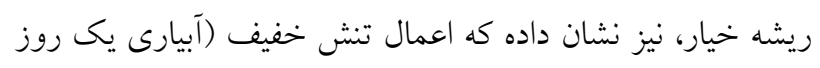

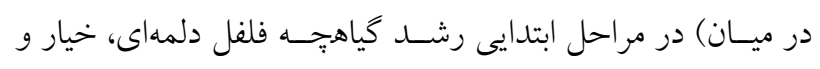

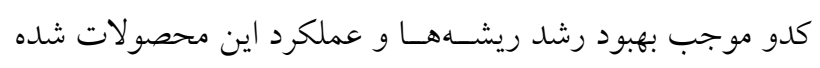

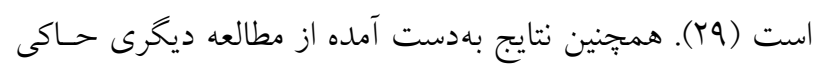

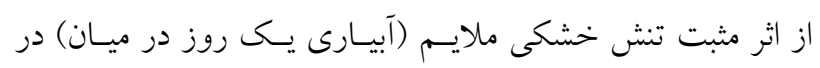

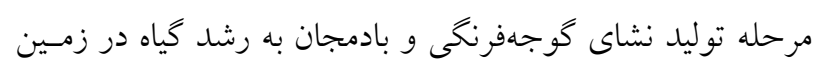

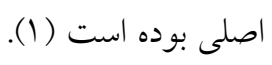

\section{وزن خشك ريشه}

نتايج بهدست آمده از تجزيه واريانس جدول (Y) نشـان داد كـه

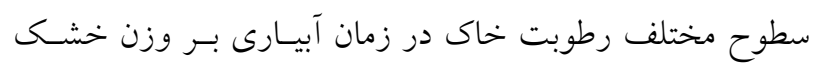

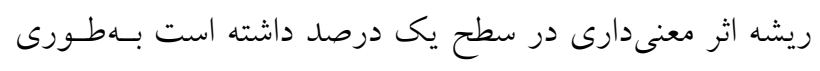

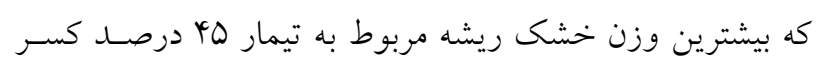
رطوبت ظرفيت مزرعه بود كه اختلاف معنى دارى با تيمارهـاى

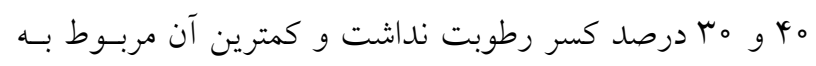

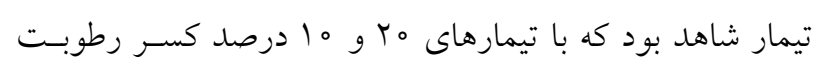

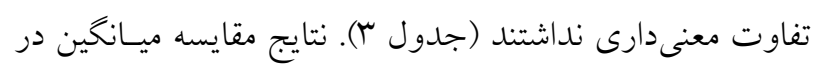

حاصل فعاليتهاى حياتى در شرايطى است كه گياه بايستى آب

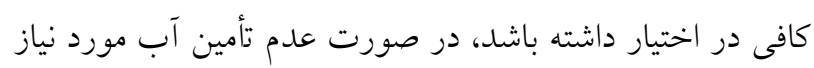

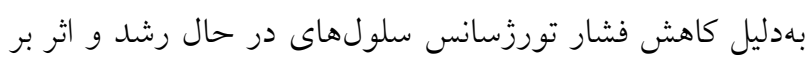

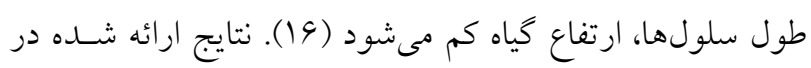

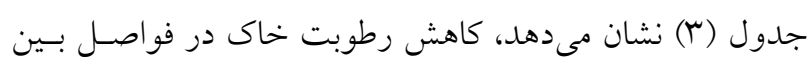

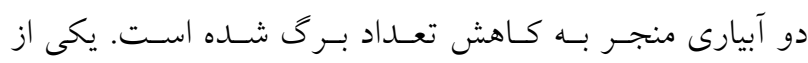

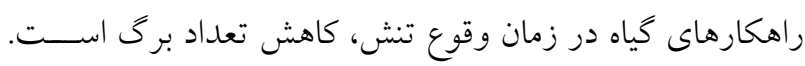

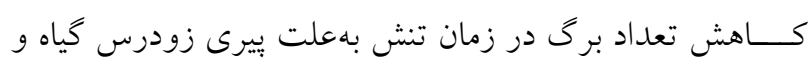

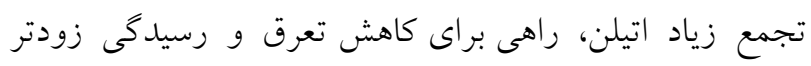
كياه براى فرار از تنش است (ب) (1).

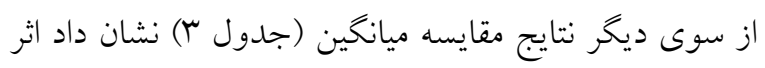

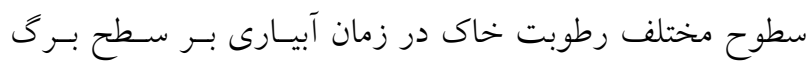

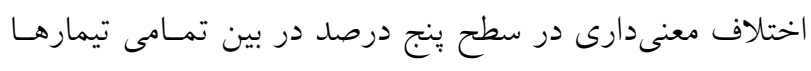

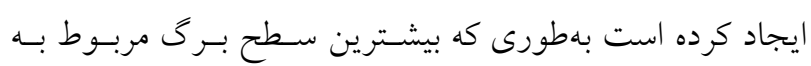

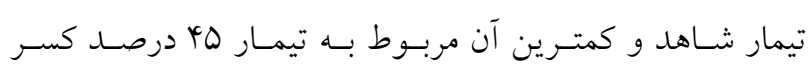

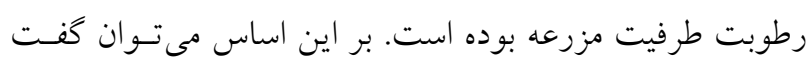

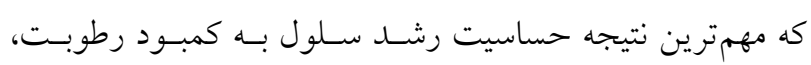

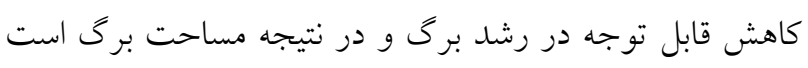

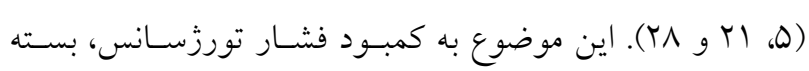

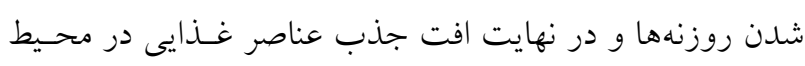

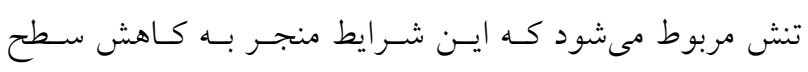

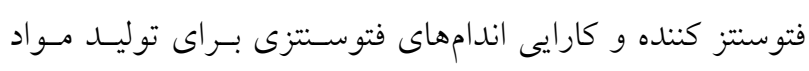

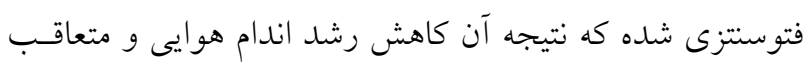

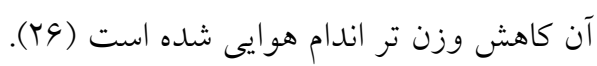

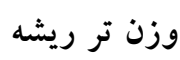
نتايج بهدست آمـده از تجزيسه واريـانس (جــدول ؟) نشـان داد كـه سطوح مختلف رطوبت خاك در زمان آبيارى، بر وزن تر ريشه اثر معنى دارى در سطح يكى درصد داشته است به طورى كـه بيشترين

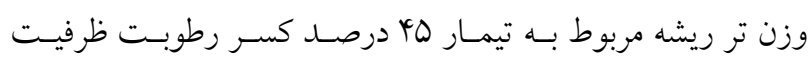

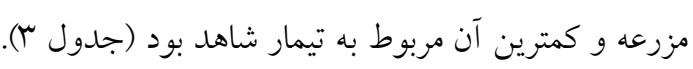

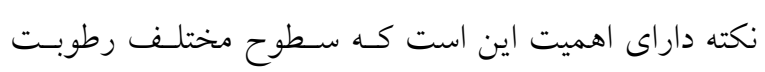


باعث افزايش بيوماس اندام هوايى نسبت بـه ريشـه و در نتيجهـ سبب افزايش اين نسبت در مقايسه با شرايط تنش شـــه اسـت.

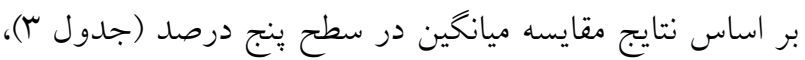

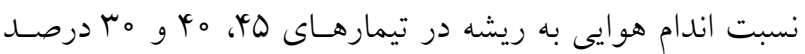

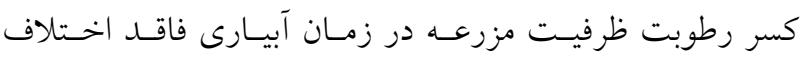

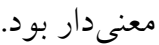
افزايش تنش اعمال شــده منجــر بــه افـزايش طـول ريشـهـ

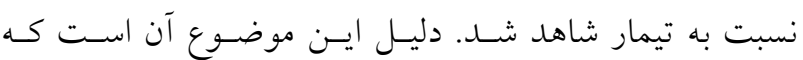
بهعلت كاهش رطوبت خاك تا نزديكى درصــ يزّمردكى در

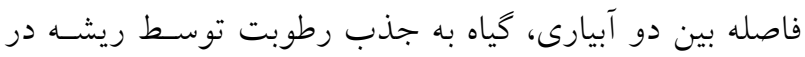

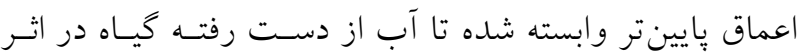

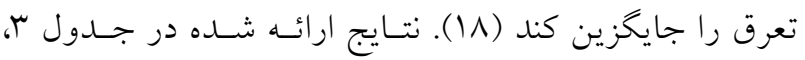

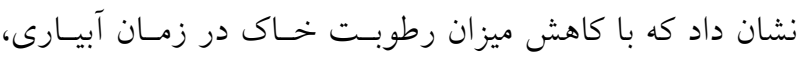

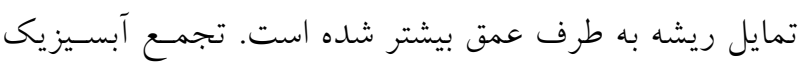

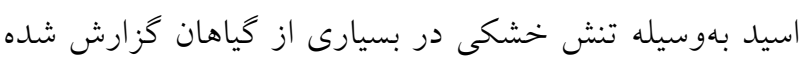

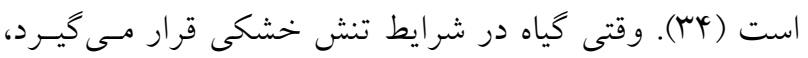

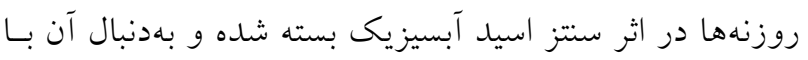
كاهش ساخت و انتقال مواد فتوسنتزى، منجر به كـاهش رشـــ

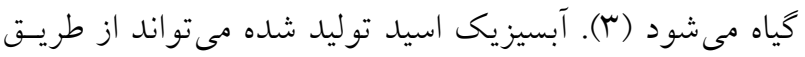

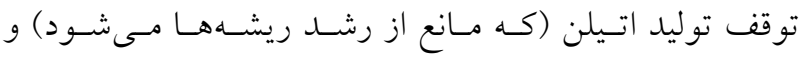

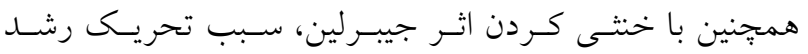
ريشهها شود (r I). در جنين شرايطى بهمنظور افزايش جـــب

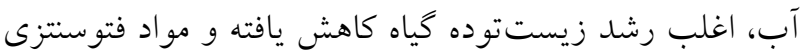

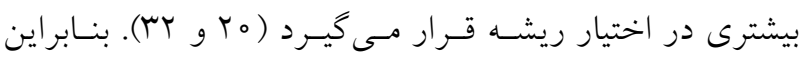

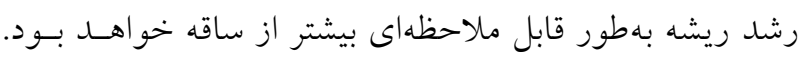

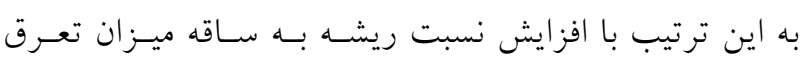

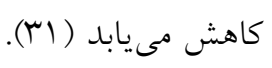

\section{شاخصهاى عملكرد ميوه خيار}

نتايج تجزيه واريانس نشان داد كه اختلاف معنى دارى در سطعح احتمال يك درصـــ بـين تيمارهـا در تعـداد ميـوه و وزن ميـوه مشاهده شد بهطورى كه بيشترين تعداد ميوه و وزن ميوه مربوط

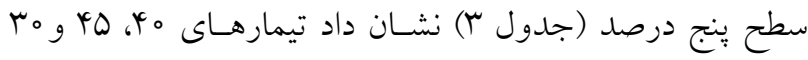
درصد كسر رطوبـت ظرفيـت و همجنـين تيمارهـاى هب، م 1 و

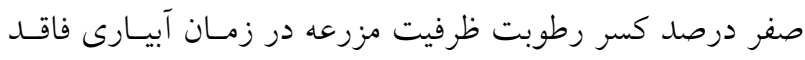

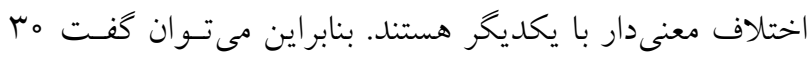

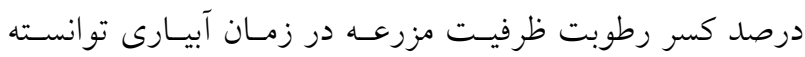
سبب افزايش وزن خشك ريشه شود.

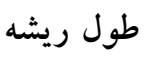
نتايج بهدست آمده از تجزيه واريانس جدول (Y) نشـان داد كـهـ سطوح مختلف رطوبت خاك در زمان آبيارى بر طول ريشه اثـر معنى دارى در سطح يك درصد داشته است بهطورى كه حداكثر

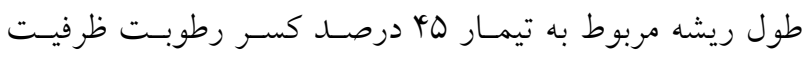
مزرعه در زمان آبيارى و كمترين آن مربوط به تيمار شاهد بـود دون.

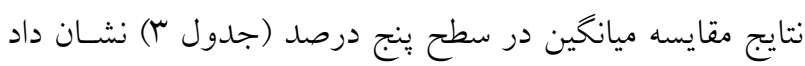

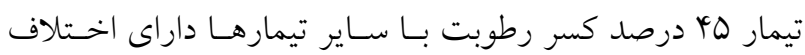

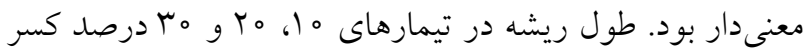
رطوبت ظرفيت مزرعه در زمان آبيارى فاقــ اخستلاف معنسى دار اين نسبت بر مبناى وزن تر اندام هوايى به وزن تـر ريشـهـ بـوده ريه

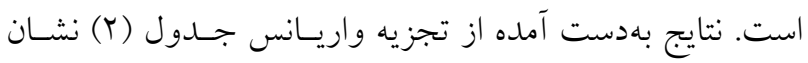

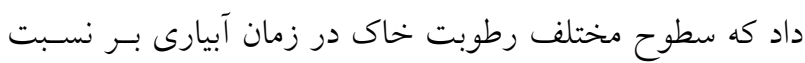

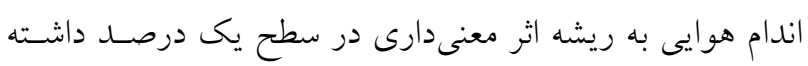

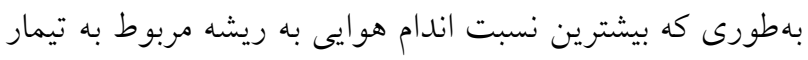

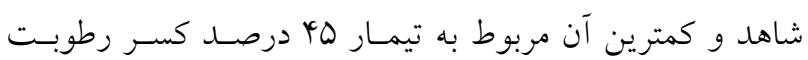
ظرفيت مزرعـه در زمـان آبيـارى بـود. نتـايج مقايسـه ميـانخين (جدول r) نشان داد كه با كاهش ميزان رطوبت خـاك در زمـان

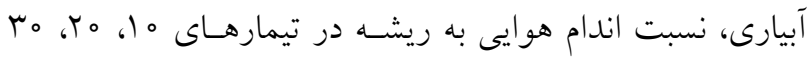

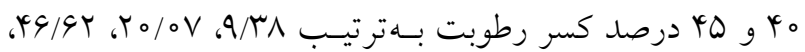

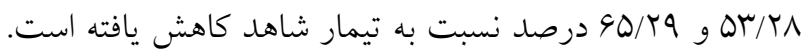

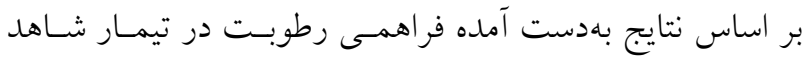


جدول f. نتايج مقايسه ميانگين اثر سطوح مختلف رطوبت خاك در زمان آبيارى بر شاخصهاى عملكرد ميوه و كارايى مصرف آب خيار

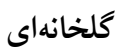

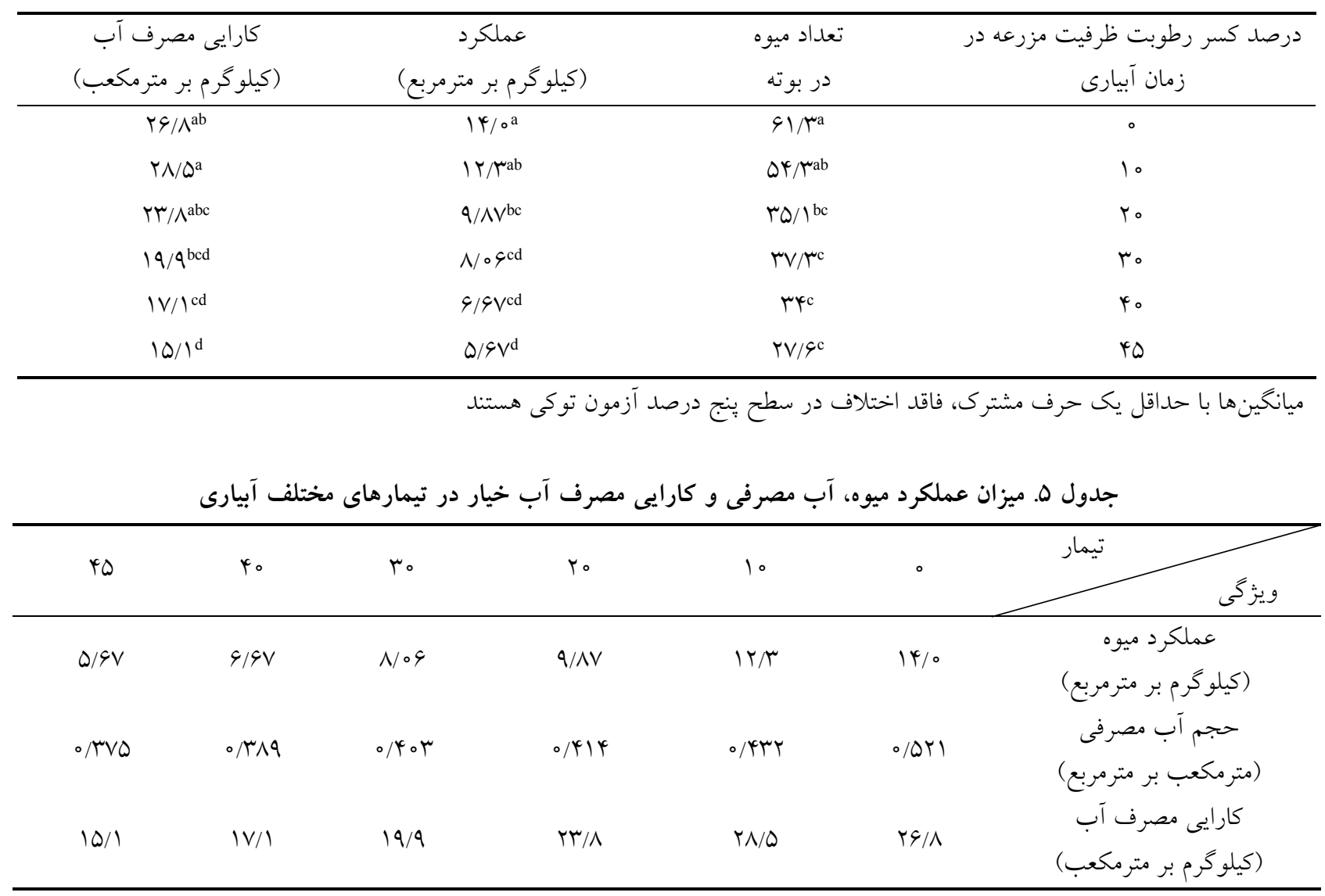

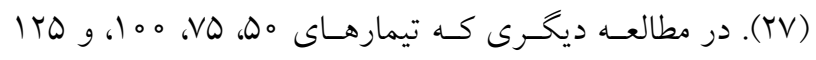

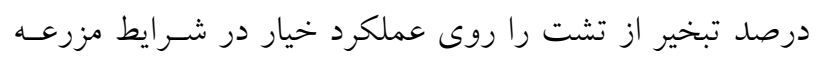

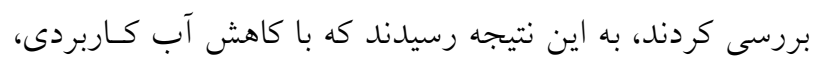

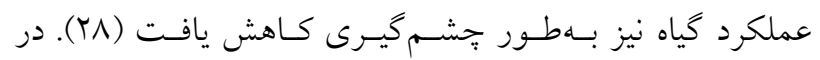

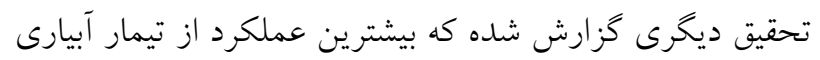

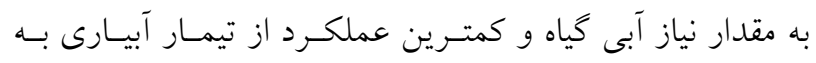

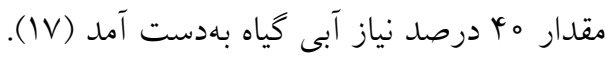

\section{كارايى مصرف آب}

نتايج تجزيه واريانس جدول (Y)، نشان داد كه اثر سطوح مختلـف

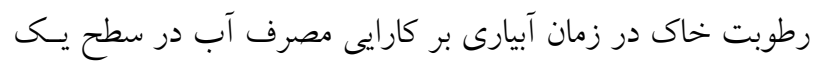

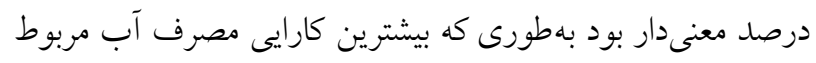

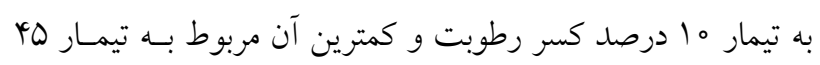

به تيمار شاهد بود كه اختلاف معنسى دارى بـا تيمـار ه 1 درصــ

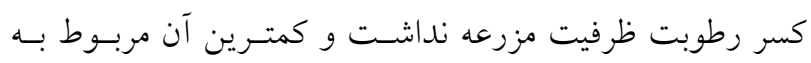
تيمار ها مرصد كسر رطوبت ظرفيت مزرعه بوده است (جدول

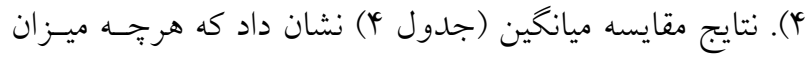

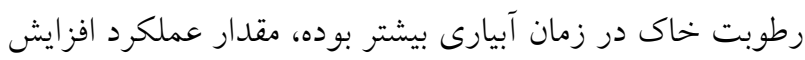

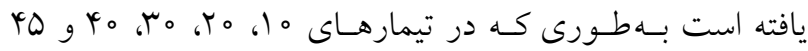
درصد كسر رطوبت ظرفيت مزرعه در زمـان آبيـارى بـهترتيـب  شاهد كاهش عملكرد مشاهده شد. در يزوهشى كه اثر سه سطح

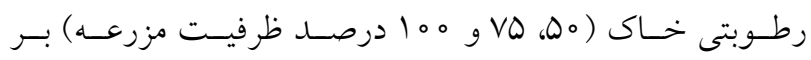

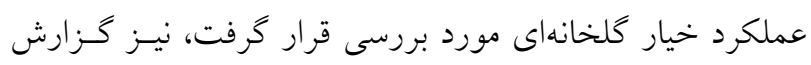

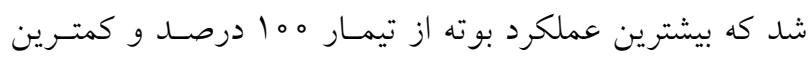

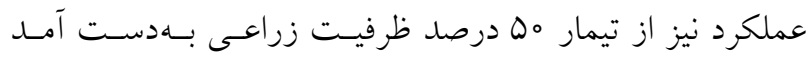




$$
\begin{aligned}
& \text { بهدست آمد و با كاهش ميزان مصرف آب بهميزان مب، مبو و }
\end{aligned}
$$

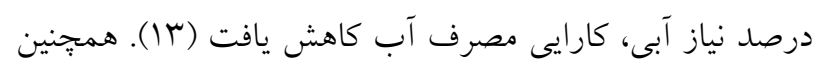

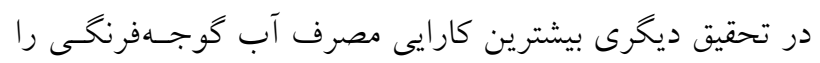

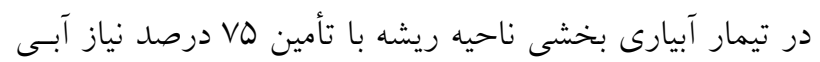

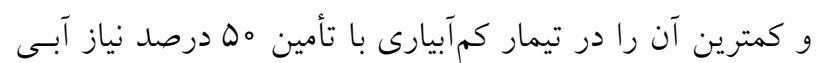

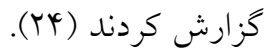

$$
\begin{aligned}
& \text { نتيجه گيرى } \\
& \text { نتايج حاصل از اين يززوهش نشـان داد كـه خيـار كلخانـهاى بـهـ } \\
& \text { افزايش دور آبيارى بسيار حساس است بهطورى كه هرجهه ميزان }
\end{aligned}
$$

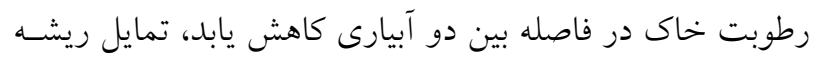

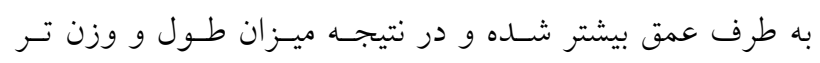

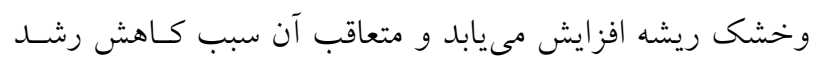

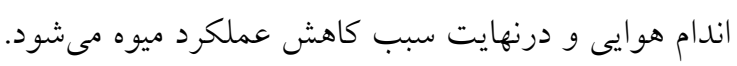

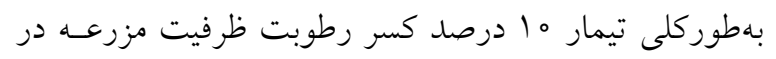

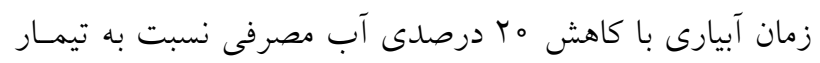

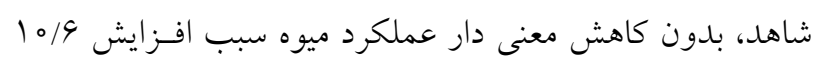

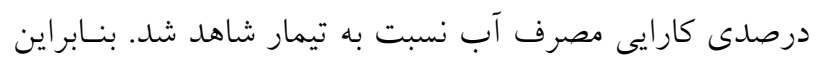

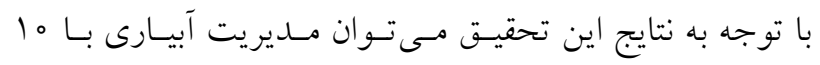

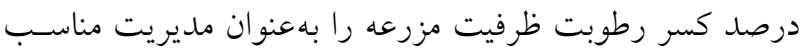

$$
\begin{aligned}
& \text { براى خيار كلخانهاى بيشنهاد كرد. }
\end{aligned}
$$

1. Ahmadi, K., H. Gholizadeh, H. R. Ebadzadeh, F. Hatami, R. Hosseinpoor, R. Kazemifard and H. Abdshah. 2016. Effects of Drought Stress on Some Morphological Characteristics of Tomato (Solanum lycopersicum), Pepper (Capsicum апnиит) and Eggplant (Solanum melongena) Seedlings after Planting in the Main Land. Agricultural Statistics Year 2015. Ministry of Jihad-e-Agriculture, Deputy Director of Planning and Economic, Information Technology Center and Communications, Tehran. (In Farsi).

2. Amer, K. H., S. A. Midan and J. L. Hatfeld. 2009. Effect of deficit irrigation and fertilization on cucumber. Agronomy Journal 101: 1556-1564.

3. Amrijit, K. N., S. Kumari and D. R. Sharma. 2005. In vitro selection and characterization of water stress tolerance culture of bell pepper. Plant Physiology 10: 14-19.

4. An, Y. Y. and Z. S. Liang. 2013. Drought tolerance of Periploca sepium during seed germination: antioxidant defense and compatible solutes accumulation. Acta Physiology Plant 35: 959-967.

5. Bagheri, A., A. Nezami and M. Sultani. 2001. Breeding for stress tolerance in cool season food Legumes. 
Agricultural Research 78:326-347. (In Farsi).

6. Bingru, H. and G. Hongwen. 2000. Root physiological characteristics associated with drought resistance in tall fescue cultivars. Crop Science 40: 196-203.

7. Buttaro, D., P. Santamaria, A. Signore, V. Cantorea, F. Boaria, F. Montesano and P. Angelo. 2014. Irrigation management of greenhouse tomato and cucumber using tensiometer effects on yield, quality and water use. Agriculture and Agricultural Science Procedia 4:440-444.

8. Dehghan, H., A. Alizadeh, K. Esmaeili and S. A. Nemati. 2015. Root growth, yield and yield components of tomato in drought stress. Journal of Water Research in Agriculture 29 (2): 169-179. (In Farsi).

9. El-Haris, M. K. and A. H. Abdel-Razek. 1997. Effect of water quantity on onion yield under sprinkler irrigation. Journal of Agriculture Research 42: 127-135.

10. Ellis, F. B. and B. T. Barnes. 1980. Growth and development of root system of winter cereals grown after different tillage methods including direct drilling. Plant and Soil 55: 283-288.

11. Eric, O. and E. S. Robert. 2007. Regulation of root growth responses to water deficit. PP. 33-53. In: Jenks, M. A., P. M. Hasegawa and S. M. Jain (Eds.), Advances in Molecular Breeding toward Drought and Salt Tolerant Crops. Springer, Berlin, Germany.

12. Glick, B. R., D. M. Penrose and J. Li. 1998. A model for the lowering of plant ethylene concentrations by plant growth-promoting bacteria. Journal of Theoretical Biology 190: 63-68.

13. Golkar, F., A. Farahmand and H. Fardad. 2008. Investigating the effect of irrigation water on yield and water use efficiency in tomato. Journal of Water Engineering 1: 13-20. (In Farsi).

14. Hakymynya, A., S. Boland nazar and S. J. Tabatabai. 2013. Limited effect of irrigation in different growth stages on vegetative traits, yield and water use efficiency of onion. Journal of Agricultural Science 23: 11-26.

15. Hanks, R. J. and G. L. Ashcroft. 1980. Applied Soil Physics. Springer-Verlag, New York.

16. Kafi, M., A. Borzouei, M. Salehei, A. Kamandi, A. Masoumi and J. Nabati. 2009. Environmental Stress Physiology in Plants. Jahad Daneshghahi Mashhad Press. Mashhad.

17. Karimi, N., A. Sadreddini, M. Nazemi, D. Farsadi zadeh, A. Hosseinzade and F. Dehghani. 2010. The effect of deficit irrigation on growth and yield of greenhouse cucumber. Journal of Water and Soil Science 20(1): 15-25. (In Farsi).

18. Kohi-Chellakaran, N., A. Alizadeh and K. Davari. 2015. The effect of different irrigation amounts on root length and grain corn yield in drip irrigation. Journal of Water Research in Agriculture 29(3): 331-340. (In Farsi).

19. Lebowski, C. A. M., R. H. Dowdy, R. R. Allmars and J. A. Lamb. 1998. Soil strength and water content influences on corn root distribution in a sandy soil. Plant and Soil 203: 239-247.

20. Liu, F. and H. Stutzel. 2004. Biomass partitioning, specific leaf area, and water use efficiency of vegetable amaranth (Amaranthus spp.) in response to water stress. Scientia Horticulturae 102: 15-27.

21. Mao, X., M. Liu, X. Wang, C. Liu, Z. Hou and J. Shi. 2003. Effects of deficit irrigation on yield and water use of greenhouse grown cucumber in the North China Plain. Agricultural Water Management 61:219-228.

22. Naderi M., M. Shayannejad, S. Heydari and B. Truth. 2016. Effect of different levels of soil moisture during irrigation on quantitative and qualitative properties of potato in Shahr-e-Kord and determining the depth of its optimum water consumption. Journal of Water and Soil 30 (5): 1370-1381. (In Farsi).

23. Nasohi. Gh. 2002. Greenhouse Cucumbers. Nosuh Press, Tehran. (In Farsi).

24. Nourmnad, N., M. R. Nouri Emamzadehi, B. Ghorbani and A. Mohammad Khani. 2007. Investigating the effect of traditional irrigation and irrigation on the yield and water efficiency of tomatoes. In: Proceeding of the Ninth Irrigation Seminar and Reduction of Evaporation, Kerman. (In Farsi).

25. Pandey, R. K., J. W. Maranville and A. Admou. 2001. Tropical wheat response to irrigation and nitrogen in a Sahelian environment. I. Grain yield, yield components and water use efficiency. European Journal of Agronomy 15: 93-105.

26. Pardo, A., M. Amato and F. Q. Chiaranda. 2000. Relationships between soil structure, root distribution and water uptake of chickpea (Cicer arietinum L.). I. Plant growth and water distribution. Europe Journal Agronomy 13: 39-45.

27. Rajaei, M., M. Attarzade, S. H. Mousavi and M. Attarzade. 2015. Use of (Glycyrrhiza glabra) compost in decreasing the effect of low water stress in greenhouse cucumber. Journal of Agricultural Science and Sustainable Production 25: 79 - 90. (In Farsi).

28. RoupHael, Y. and C. Giuseppe. 2005. Radiation and water use efficiencies of greenhouse zucchini squash in relation to different climate parameters. European Journal of Agronomy 23: 183-194.

29. Sadeghi, M., A. Ahmadian, H. Gholami tile bani and A. Gulpaygani. 2011. Effect of drought stress on morphological characteristics in the seedling of cucumber (Cucumis sativs) pepper (Capsicum annuum) and pumpkin (Legenaria vulgaris) after planting in the ground operation. In: Proceeding of the First National Conference on Strategies to Achieve Sustainable Agriculture, Ahvaz, Khuzestan Province PNU. (In Farsi).

30. Simsek, M., T. Tonkaz, M. Kaclra, N. Comlekcioglu and Z. Dogan. 2005. The effects of different irrigation regimes on cucumber (Cucumbis sativus L.) yield and yield characteristics under open field conditions. Agricultural 
Water Management 73: 173-191.

31. Singh, P. 1991. Influence of water deficits on Phenology, growth and dry mater allocation in chickpea (Cicer arietinum). Field Crops Research 28: 1-15.

32. Villagra, P. E. and J. B. Cavagnaro. 2006. Water stress effects on the seedling growth of Prosopis argentina and Prosopis alpataco. Journal of Arid Environment 64: 390-400.

33. Voldabadi, S. A. and H. Abadi Farahani. 2008. Effect of potassium application on quantitative properties and root development in corn, sorghum and millet under drought stress conditions. Iranian Journal of Agronomy and Plant Breeding 4: 37-48.

34. Yang, J., X. loui, B. Kiu, J. Li and D. He. 2004. Hormonal changes in plants grown under reduced irrigation. Journal of Central European Agriculture 10: 123-129. 


\title{
Effects of Soil Moisture Deficit Levels at Irrigation time on Shoot and Root Growth Indices, Yield and Water Use Efficiency of Greenhouse Cucumber
}

\author{
A. Shafaei ${ }^{1}$, A. Karimi ${ }^{2}$ and R. Barzegar ${ }^{3^{*}}$
}

(Received: January 15-2018; Accepted: July 7-2018)

\begin{abstract}
The aim of this study was to evaluate the effect of different levels of soil moisture at irrigation time on root growth, yield and water use efficiency of greenhouse cucumber (Cucumis sativus L.), Yalda cultivar. The experiment was conducted in a randomized complete block design with six treatments and three replications in Isfahan Greenhouse Research Center in 2016. These experimental treatments included: field capacity (FC), $10 \% \mathrm{FC}, 20 \% \mathrm{FC}, 30 \% \mathrm{FC}, 40 \%$ FC and $45 \%$ FC. Therefor, Irrigation was carried out after reducing the soil moisture to above values. In this experiment, plant height, leaf number, fresh weight of shoot, average leaf area, root length, root fresh weight, root dry weight, shoot to root ratio, fruit number, yield and water use efficiency were measured. The results showed that different levels of soil moisture at irrigation time had significant $(\mathrm{p}<0.05)$ effect on root growth, yield and water use efficiency of greenhouse cucumber. The results also indicated that root growth decreased with increasing soil moisture content. The highest root length, fresh and dry weight of the root were achieved with the treatment of $45 \%$ moisture content of the field capacity at irrigation time. The highest yield was obtained in FC and 10\% FC treatments. The results showed that the best treatment was $10 \% \mathrm{FC}$ treatment due to highest water use efficiency $\left(5.28 \mathrm{~kg} \cdot \mathrm{m}^{-3}\right)$ and yield $(12.3$ kg. $\left.\mathrm{m}^{-2}\right)$.
\end{abstract}

Keywords: Field capacity, Fruit number, Shoot to root ratio, Water Stress, Yield

1, 2. MSc. Student and Assistant Professor, Respectively, Department of Soil Science, Agriculture Faculty, Shahrekord University, Shahrekord, Iran.

3. Assistant Professor, Department of Horticulture Science, Agriculture Faculty, Shahrekord University, Shahrekord, Iran.

*: Corresponding Author, Email: barzegar56@yahoo.com 